\title{
Is It Unethical for Psychiatrists to Give an Opinion on a Public Figure's Mental State?
}

\author{
Heon-Jeong Lee, MD, PhD, Editor-in-Chief \\ Department of Psychiatry, Korea University College of Medicine, Seoul, Republic of Korea
}

Is there an ethical problem with psychiatrists' diagnosis of a public figure based on public information without direct evaluation? In this issue of the journal, there is a Viewpoint article about the Goldwater rule. ${ }^{1}$ The Goldwater rule is an ethical principle that guides psychiatrists not to provide an opinion on the mental health of someone they have not examined in person and without the patient's consent or other legal authority. ${ }^{2}$

Before her impeachment was passed in South Korea in 2017, several mental health professionals suggested psychiatric problems of former President Park Geun-hye via the media. Their diagnoses were autism, teenage mentality, dependent personality, shared psychosis, and so on. ${ }^{3}$ Recently, in the United States, mental health experts' concerns about President Trump's mental health are being reported in various media, and there is a debate concerning conflict between the Goldwater rule and mental health professionals' "duty to warn" the public about the mental health of a person in power. ${ }^{4}$ The Goldwater rule has obviously become controversial in the era of Donald Trump.

Recently in South Korea, there has been an ethical issue concerning a psychiatrist mentioning the possibility and risk of psychiatric illness of a famous actor without a direct interview. ${ }^{5}$ The psychiatrist has observed that the actor was engaging in debate with a large number of people on SNS and mentioned that he seemed to be in an acute hypomanic state and that he had a risk of suicide on SNS. In relation to this issue, the psychiatrist has received many criticisms from psychiatrist societies and the public, yet there is also a position advocating this behavior, as in the case of Trump. In this regard, controversy arises, such as ethical issues in Korean psychiatrist societies. However, this case is different from Trump's, as it is unlikely that the actor will have a great influence on risks to society, so it is hard to avoid criticism for publicly speaking about the mental health of person who has not been directly evaluated. Furthermore, the duty to warn is a legal concept that generally requires psychiatrists to breach the confidentiality of a therapeutic session when a risk of danger to others becomes known during treatment of the patient. It does not apply if there is no physician-patient relationship.

Unfortunately, there is no discussion of the Goldwater rule nor has "duty to warn" been discussed in Korean psychiatrist societies. It seems that there should be a public discussion of these issues in Korean psychiatrist societies.

\section{REFERENCES}

1. Park SC. The Goldwater rule from the perspective of phenomenological psychopathology. Psychiatry Investig 2018;15:102-103.

2. American Psychiatric Association. Principles of Medical Ethics with Annotations, 2010 Edition, Section 7. American Psychiatric Association. Available at: http://www.psych.org/MainMenu/PsychiatricPractice/Ethics/ResourcesStandards/Principles-of-Medical-Ethics-2010-Edition. aspx?FT=.pdf. Accessed January 28, 2018.

3. Does South Korean President have 'teenage' mentality? Available at: http://www.koreatimes.co.kr/www/news/nation/2016/11/116_218441. html. Accessed January 29, 2018.

4. McCarthy M. Experts debate Trump's mental health in US press. BMJ 2017;356:ز864.

5. Psychiatrist expresses concerns about Yoo Ah-In's mental health. Available at: http://www.koreadailyus.com/psychiatrist-expresses-concernsyoo-ah-ins-mental-health. Accessed January 29, 2018.

(c) This is an Open Access article distributed under the terms of the Creative Commons Attribution Non-Commercial License (http://creativecommons.org/licenses/bync/4.0) which permits unrestricted non-commercial use, distribution, and reproduction in any medium, provided the original work is properly cited. 